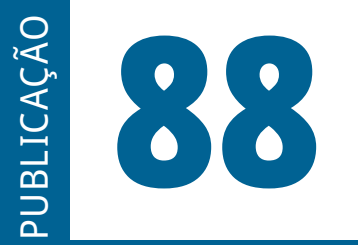

ISSN: 0101-9562

ISSN ELETRÔNICO: 2177-7055

SEQÜÊNCIA

Publicação do

Estudos jurídicos

e políticos

Programa de Pós-Graduação em Direito da UFSC

VOLUME 42 - ANO 2021 
SEQUÊNCIA - ESTUDOS JURÍDICOS E POLÍTICOS é uma publicação temática e de periodicidade quadrimestral, editada pelo Programa de Pós-Graduação Stricto Sensu em Direito da Universidade Federal de Santa Catarina - UFSC.

SEQUÊNCIA - ESTUDOS JURÍDICOS E POLÍTICOS is a thematic publication, printed every four months, edited by the Program in law of the Federal University of Santa Catarina - UFSC.

Versão eletrônica: http://www.periodicos.ufsc.br/index.php/sequencia

A publicação é indexada nas seguintes bases de dados e diretórios/

The Publication is indexed in the following databases and directories:

Base OJS

Base PKP

CCN (Catálogo Coletivo Nacional)

Dialnet

DOAJ (Directory of Open Access Journals)

EBSCOhost

Genamics Journalseek

ICAP (Indexação Compartilhada de Artigos de Periódicos)

Latindex

LivRe!

OJS
PKP
Portal de Periódicos UFSC
Portal do SEER
ProQuest
SciELO
Sherpa/Romeo
Sumarios.org
ULRICH'S
vLex

Ficha catalográfica

Seqüência: Estudos jurídicos e políticos. Universidade Federal de Santa Catarina.

Programa de Pós-Graduação em Direito. n.1 (janeiro 1980)-.

Florianópolis: Fundação José Boiteux. 1980-.

Publicação contínua

Resumo em português e inglês

Versão impressa ISSN 0101-9562

Versão on-line ISSN 2177-7055

1. Ciência jurídica. 2. Teoria política. 3. Filosoia do direito. 4. Periódicos.

I. Universidade Federal de Santa Catarina. Programa de Pós-graduação em

Direito

CDU 34(05)

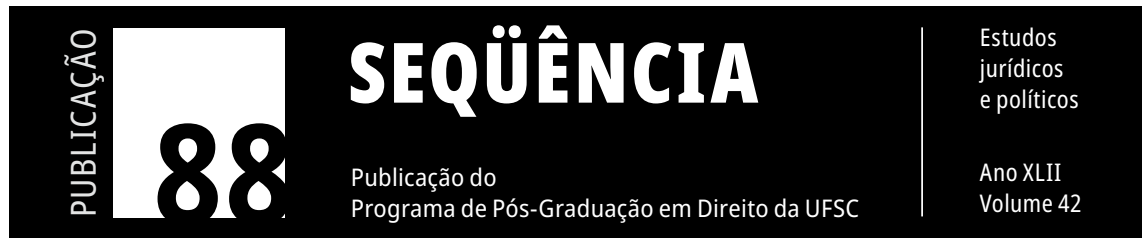




\title{
Identidades que (trans)bordam nos espaços burocráticos: a OC 24/2017 da Corte Interamericana de Direitos Humanos e sua repercussão nos autos da ADI 4275/DF
}

\author{
Identities that (trans)border buchractical locals: the \\ OC 24/2017 of the Inter-American Court of Human \\ Rights and its repercussion on ADI 4275/DF
}

\author{
Pâmela Copetti Ghisleni \\ Faculdade CNEC Santo Ângelo, Santo Ângelo, Brasil \\ Doglas Cesar Lucas \\ Universidade Regional do Noroeste \\ do Estado do Rio Grande do Sul, Ijuí, Brasil
}

RESUMO: Este texto tem como objetivo analisar de que maneira o tema dos direitos sexuais vem sendo incorporado à agenda do Sistema Interamericano de Direitos Humanos, especialmente no que diz respeito à temática das pessoas transgêneras e transexuais. Para tanto, vale-se de importante e recente Opinião Consultiva (OC) 24/17, sem deixar de perceber os relevantes reflexos deste instrumento no direito pátrio brasileiro, especialmente a partir da Ação Declaratória de Inconstitucionalidade (ADI) 4275/DF, do Supremo Tribunal Federal, evidenciando-se um possível e fecundo diálogo das Cortes. O método utilizado é o fenomenológico hermenêutico.

Palavras-CHAVE: Identidade - Registro Civil - Sistema Interamericano - Transgeneridade.

ABSTRACT: This text aims to analyze how the issue of sexual rights has been incorporated into the agenda of the Inter-American Human Rights System, especially with regard to the issue of transgender and transsexual persons. For this, it is based on an important and recent Consultative Opinion (OC) 24/17, without neglecting 
to perceive the relevant reflexes of this instrument in the Brazilian homeland law, especially from the Declaratory Action of Unconstitutionality (ADI) 4275/DF, of the Federal Supreme Court, evidencing a possible and fruitful dialogue of the Courts. The method used is the phenomenological hermeneutic.

KEY WORDS: Identity - Civil Registration - Inter-American System - Transgenerity.

\section{INTRODUÇÃO}

No mundo contemporâneo, a sexualidade e a identidade de gênero introduziram em seu contexto o amor, o afeto o romance e a singularidade. Com isso, invariavelmente, tornaram-se processos extremamente complexos de conformação de subjetividades autênticas, estando, também invariavelmente, atravessadas pela própria noção de dignidade da pessoa humana. É dizer, projetamos em nossas experiências sexuais e amorosas um fator de reconhecimento tanto ou mais importante do que fazemos com relação às nossas possibilidades financeiras ou intelectuais, por exemplo. Isso significa que o gênero e a sexualidade possibilitam o reconhecimento ou a sensação de perda de valor próprio, a depender das circunstâncias. Com isso, a sexualidade e a identidade de gênero tornam-se elementos-chave na imensa gama de identidades que compõem (e por vezes, numa perspectiva castradora, normalizam) o ser.

Essa transformação, rapidamente acolhida em diversos campos do conhecimento humano, ainda caminha a passos lentos na cena jurídica, inclusive na seara dos direitos humanos e especialmente do ponto de vista legislativo. Nesse sentido, questiona-se: é importante para o Estado e para o Direito o que as pessoas sentem? O corpo ou a pele que habitam? A forma como desejam? Quem desejam? Este artigo posiciona-se claramente favorável a tais questionamentos, o que não significa um clamor à regulação jurídico-legal nos melindres do tema, muito antes pelo contrário, conforme demonstrar-se-á ao longo da pesquisa.

O recorte teórico escolhido é aquele da Opinião Consultiva (OC) $\mathrm{n}^{\circ}$ 24/17, exarada pela Corte Interamericana de Direitos Humanos (CDH) 
em 24 de novembro de 2017. A partir deste importante parecer, pretende-se compreender de que maneira essa complexidade do mundo contemporâneo, esse libertar dos corpos, da palavra e dos gestos repercutiu no Direito e nas políticas de Estado, levando em consideração especialmente a Ação Direta de Inconstitucionalidade (ADI) 4275/DF.

Para realização do estudo, adotou-se como base a fenomenologia hermenêutica, consistente na revisão crítico-reflexiva dos temas transmitidos pela tradição filosófica por meio da linguagem. Essa abordagem permite a análise dos fenômenos estudados no plano da historicidade, favorecendo a compreensão de que o "fazer jurídico" é mais do que um ato passivo de subsunção (STRECK, 2014). Esse horizonte metodológico, portanto, surge como um campo fértil e adequado à discussão da temática objeto desta pesquisa.

\section{SITUANDO (LOCAL E HISTORICAMENTE) 0 DEBATE: O SISTEMA INTERAMERICANO DE DIREITOS HUMANOS E A PROTEÇÃO DAS MINORIAS SEXUAIS}

Previamente ao enfrentamento dos atos jurisdicionais centrais desta pesquisa, é salutar desenvolver breves apontamentos acerca do Sistema Interamericano de Direitos Humanos (SIDH) e dos seus aspectos procedimentais, sem os quais a compreensão da própria gênese e dos fundamentos da OC 24/17 fica prejudicada.

O SIDH, na condição de sistema regional, caminha lado a lado com o sistema global (alicerçado na Organização das Nações Unidas - ONU) e compreende uma região marcada por elevado grau de exclusão e desigualdade social, na qual persistem enraizadas a violência e a impunidade. Então, dois fatores fundamentais marcam o contexto latino-americano: o período dos regimes ditatoriais e a transição para os regimes democráticos, na década de 1980, na Argentina, Chile, Uruguai e Brasil. Nesses períodos ditatoriais, os mais básicos direitos 
e liberdades foram violados. Execuções sumárias, desaparecimentos forçados, torturas sistemáticas, prisões ilegais e arbitrárias, perseguições políticas e abolição das liberdades de expressão, reunião e associação fizeram parte do cotidiano dos cidadãos (Piovesan, 2006).

Não se pode esquecer, além disso, que o sujeito latino-americano personifica justamente a ideia do outro, do bárbaro, tendo em vista que a América colonizada pelos portugueses e espanhóis foi apropriada (e castrada) pelo discurso moderno do Eu europeu universalizado e abstrato.

Entretanto, é importante conjugar nessa análise o fato de que atualmente existe um movimento tendente a afirmar uma posição diferente da sociedade latino-americana em relação ao seu passado de exclusão e exploração, fortalecendo percepções outras que escapem dos reducionismos que analisam negativamente a região e seu povo (Lucas; Cenci, 2015). Com efeito, "todo la historia de Latinoamérica, al menos desde que el europeo llego a ella, es historia de derechos humanos" (ZAFFARONI, 1989, p. 22), de modo que se cada fração de consciência do nosso ser está colonizada pela opressão a que o povo latino-americano foi submetido, essa mesma fração consciente tem a lúcida percepção de que temos direitos.

Por conseguinte, nesse contexto de fracas democracias, exclusão, desigualdade social, impunidade, violência e colonialidade, não surpreende que parcela considerável das represálias verificadas no continente desague justamente na sexualidade e na identidade de gênero dos indivíduos, motivo pelo qual assume especial relevância a análise dos direitos sexuais na América Latina e no sistema regional a ela vinculado, do qual falar-se-á nos parágrafos seguintes.

Basta pensar que, segundo o Informa sobre a Violência de Pessoas LGBTI nas Américas, de 2015, elaborado pela Comissão Interamericana (CIDH, 2015), 11 Estados-membros da Organização dos Estados Americanos (OEA) mantêm leis que criminalizam as relações sexuais consensuais entre pessoas adultas do mesmo sexo. A designação varia de país para país, podendo ser encontradas as seguintes tipificações 
normativas: "sodomia", "delitos contra a ordem natural" ou "crimes de conexão não natural".

A Comissão destaca que muito embora essas leis sejam destinadas a regular as relações sexuais, isto é, abarcando a noção de orientação sexual, as pessoas trans (e, nesse sentido, considerando-se a identidade de gênero) quase que invariavelmente enfrentam violência e discriminação nesses contextos, até mesmo em virtude de sua grande vulnerabilidade e alto grau de exposição (CIDH, 2015).

Em 2018, a Comissão lançou novo Informe acerca dos avanços e desafios para o reconhecimento dos direitos de pessoas LGBTI nas Américas, oportunidade em que lamentou que, "a pesar de las recomendaciones formuladas en dicho informe, todas esas normas sigan vigentes en los referidos Estados, en violación de sus obligaciones internacionales relativas al derecho a la igualdad y no discriminación." (CIDH, 2018, p. 124).

Feitos esses esclarecimentos, justificando a importância do estudo dos direitos sexuais no cenário latino-americano, passa-se enfim à explanação acerca dos aspectos normativos e procedimentais do Sistema Interamericano.

A ideia globalizante de direitos humanos universais é enriquecida e inclusive contestada pelas particularidades regionais. É por influência dessa dinâmica que surge, no âmbito da Organização dos Estados Americanos (OEA), o SIDH, que se compõe, basicamente de dois instrumentos ou regimes: um baseado na Carta da OEA e outro na Convenção Americana (Pacto de San José da Costa Rica).

Em linhas gerais, pode-se afirmar que o Pacto de San José da Costa Rica conta com um aparato que é integrado pela Comissão Interamericana de Direitos Humanos (CIDH) e pela Corte Interamericana (Corte IDH), responsável pelo monitoramento e implementação daqueles direitos que enuncia, tendo como principal função a observância e proteção dos direitos humanos nas Américas.

A Comissão Interamericana de Direitos Humanos tem competência perante todos os Estados da Convenção Americana 
relativamente aos direitos humanos nela previstos, e perante todos os Estados-membros da OEA quanto aos direitos garantidos na Declaração Americana de 1948. A Comissão conta com sete membros, eleitos pela Assembleia Geral para um período de quatro anos, possibilitando-se a reeleição apenas uma vez, nos termos dos artigos 34 e 37 da Convenção Americana.

Dentre as importantes atribuições da Comissão, pode-se mencionar a elaboração de relatórios conclusivos informando se o Estado violou ou não a Convenção Americana. Esse relatório é enviado ao Estado-parte que, se não der cumprimento às recomendações no prazo, pode ser denunciado perante a Corte Interamericana. A partir daí, há um "quê" de juridicidade no procedimento. Isso porque a Corte Interamericana é composta por sete juízes nacionais de Estados membros da OEA, tendo competências consultiva (interpretação das disposições da Convenção Americana e também dos tratados relativos à proteção de direitos humanos nos Estados Americanos) e contenciosa ou jurisdicional (solução de controvérsias que se apresentem sobre a aplicação ou interpretação da própria Convenção). Todavia, o caso somente pode ser submetido à Corte se houver declaração expressa e específica do Estado reconhecendo a competência da Corte para tanto (artigo 62), o que muitas vezes coloca em xeque a efetividade do procedimento por supostamente enfraquecer o sistema.

É especialmente relevante para esta pesquisa a atuação consultiva da Corte Interamericana, na medida em que se propõe, neste texto, uma breve abordagem em torno da OC 24/17 e da sua repercussão na recente ADI 4275/DF, a respeito das quais discorrer-se-á no terceiro ponto desta pesquisa.

Com efeito, por força do artigo 64 do Protocolo de San José da Costa Rica, os Estados-membros da OEA poderão consultar a Corte sobre a interpretação do próprio Protocolo (Convenção Americana de Direitos Humanos) ou de outros tratados relativamente à proteção de direitos humanos nos Estados americanos. O artigo 14.2 assevera, ainda, que a pedido de um Estado-membro da OEA, a Corte pode 
emitir parecer sobre a compatibilidade entre suas leis internas e mencionados instrumentos internacionais.

Verifica-se, portanto, que a função consultiva da Corte está alicerçada no artigo 64 da CADH, sendo disciplinada em suas nuanças nos artigos 70 a 75 do seu Regulamento. Seja em virtude da extensão do objeto da consulta, seja pela imensa gama de legitimados a solicitá-la, a Corte exerce, sem dúvidas, uma função ímpar no Direito Internacional contemporâneo, uma das mais abrangentes de que já encarregado um tribunal internacional.

Além dos órgãos e documentos mencionados, o Sistema Interamericano possui um conjunto bastante amplo de legislação específica, destacando-se, para o tema em análise, a Convenção Interamericana para Prevenir, Punir e Erradicar a Violência contra a Mulher, realizada em 1994 e a Resolução no 2435/2008 da Assembleia Geral da Organização dos Estados Americanos, e suas alterações subsequentes (RES n's 2863/2014, 2807/2013, 2721/2012, 2653/2011, 2600/2010, 2504/2009).

Importa frisar também a criação, em 2011, a cargo da Comissão Interamericana de Direitos Humanos, da Unidade para os Direitos de Pessoas Lésbicas, Gays, Bissexuais, Transexuais e Intersexuais (LGBTI), com enfoque em temas como orientação sexual, identidade, expressão de gênero e diversidade corporal. A ela, seguiu-se a relatoria sobre o direito de pessoas LGBTI, cujas atividades foram formalmente iniciadas em fevereiro de 2014 com a indicação da Comissária Tracy Robinson para Relatora. Atualmente, conforme já mencionado, essa importante atribuição está a cargo da jurista brasileira Flávia Piovesan, eleita pela Assembleia Geral da OEA para um período de quatro anos, iniciando-se em $1^{\circ}$ de janeiro de 2018 e findando em 31 de dezembro de 2021.

Ainda, a Convenção Interamericana contra Toda Forma de Discriminação e Intolerância, aprovada em 2013, constitui-se num importante instrumento de repúdio à discriminação e violência contra os grupos LGBTI. Sua eficácia deriva em boa parte do fato de que é 
o primeiro documento internacional que vincula, expressa e juridicamente, condenando a discriminação baseada em orientação sexual, identidade e expressão de gênero.

É de se mencionar, também, que organizações como o Comitê Latino-americano e do Caribe para a Defesa dos Direitos da Mulher (CLADEM), a Rede Latino-americana e Caribenha de Jovens pelos Direitos Sexuais e Reprodutivos e a Comissão Internacional de Direitos Humanos para Gays e Lésbicas, ao lado de outras instituições, alavancaram, a partir de 2002, uma Campanha por uma Convenção Interamericana dos Direitos Sexuais e dos Direitos Reprodutivos. Entretanto, as últimas notícias disponíveis na rede relativamente à Convenção são de 2005.

Por fim, não há como deixar de lembrar dos Princípios de Yogyakarta, frutos de uma reunião de especialistas, realizada na Indonésia entre 6 e 9 de novembro de 2006. 29 especialistas de 25 países, com experiências diversas e conhecimento relevante em termos de direitos humanos, adotaram por unanimidade os chamados Princípios de Yogyakarta sobre a Aplicação da Legislação Internacional de Direitos Humanos em relação à Orientação Sexual e Identidade de Gênero. Em que pese esse instrumento normativo não tenha sido entabulado especificamente no âmbito da OEA, o fato é que ele repercute de maneira muito especial nas interpretações realizadas pela Corte Interamericana, inclusive na própria OC 24/17, oportunidade em que é mencionado por diversas vezes. Inclusive, no tocante à identidade de gênero, existe previsão expressa, no artigo 18 do documento, de proteção em face de quaisquer abusos médicos, tema central quando se trata de discutir o direito ao nome de pessoas trans.

Mas o instrumento mais importante que talvez tenha sido encetado pelo Sistema Interamericano de Direitos Humanos diz respeito à Opinião Consultiva n ${ }^{\circ}$ 24/2017, de 24 de novembro de 2017 e recentemente divulgada no site da Corte, a respeito da qual discorrer-se-á oportunamente, em paralelo com a importante decisão do Supremo Tribunal Federal nos autos da ADI 4275/DF. 


\section{ORIENTAÇÃO SEXUAL E IDENTIDADE DE GÊNERO: CATEGORIAS EM DISPUTA}

Previamente à discussão envolvendo o estudo dos casos em análise, é fundamental prefaciar este tópico com alguns conceitos elementares necessários à compreensão adequada dos direitos inerentes à orientação sexual e à identidade de gênero. É que nos seres humanos, a sexualidade adquiriu outras dimensões que articulam não somente aspectos biológicos e psicológicos, mas também sociais e culturais, a começar pelo fato de que apenas os seres humanos fizeram da sua atividade sexual uma experiência erótica, um itinerário independente da sua programação biológica para reproduzir e perpetuar a espécie (BAtaille, 2014).

O primeiro conceito a ser elucidado é o de sexualidade, "invenção" do século XVIII. Invenção porque é desse momento em diante que o sexo e os atos corporais que tinham por objetivo a obtenção e produção de prazer adquirem um conteúdo próprio que diz do sujeito, que fala de si e do outro, enunciando a sua verdade interna. Sendo assim, a sexualidade pode ser abordada a partir de uma série de pontos de vista. Trata-se, consequentemente, de um conceito difuso, fluído, empírico, analítico e político, o qual envolve as experiências individuais e coletivas, bem como a psique e a cultura. No itinerário do mundo ocidental, não se pode negar que a sexualidade é hoje (e cada vez mais) um rasgo radicalmente importante para a explicação em torno de quem o sujeito é.

Outra categoria importante é a identidade de gênero. A formulação beauvoriana (2009, p. 361) segundo a qual "ninguém nasce mulher: torna-se mulher", possivelmente ilustra a manifestação primeira do conceito. Problematizar a biologização e o determinismo dos corpos em uma perspectiva de gênero implica rejeitar as justificativas essencialistas e naturalizantes. Nesse sentido, Butler (2016) historiciza o corpo e o sexo, apartando a dicotomia sempre presente de sexo-gênero. Em sua percepção, dita bipartição fornece possibilidades 
limitadas às feministas relativamente às questões que elas desejam enfrentar. A própria noção de "mulheres" como sujeitos e protagonistas do feminismo é problematizada por Butler (2016), no sentido de que talvez ela só sirva e funcione sob a lógica da matriz heterossexual. Por isso, Scott (1989) também critica os vícios do pensamento ocidental, a fim de que seja possível relativizar as noções de homem e mulher, masculino e feminino, as quais perpetuam o discurso responsável pela manutenção de uma ordem compulsória.

Foucault (2012) também foi uma referência importante para tais teóricas na medida em que discorreu sobre o poder e a sexualidade de uma maneira relativamente inovadora. Para o autor, o poder jamais estabelece uma relação profícua em relação ao sexo. Nesse ínterim, o poder é aquilo que diz a lei, o que implica reduzir o sexo a um regime binário de licitude e ilicitude. Por isso, "a forma pura do poder se encontraria na função do legislador; e seu modo de ação com respeito ao sexo seria jurídico-discursivo.” (Foucault, 2012, p. 94). De fato, na lógica foucaultiana (2012), o poder sobre o sexo se exerce em todos os níveis, assumindo a forma do direito por excelência, seja na perspectiva do pai que proíbe, do príncipe que faz o direito, do mestre que orienta ou do censor que reprime. Todas estas formas são esquematizações do poder a partir de formas jurídicas (de lei) e que definem obediências.

Em resumo, a genitália não (deveria) determina(r) se o corpo é feminino ou masculino, na medida em que esses conceitos são construídos pela sociedade. E, se determinar - pois desconstruções são realmente complexas e como sociedade ainda precisamos que as identidades comuniquem do (e para) os sujeitos - isso não pode ser concebido a partir de uma ordem hierárquica. Por isso, para Scott (1989, p. 21), “o gênero é um elemento constitutivo das relações sociais baseado nas diferenças percebidas entre os sexos." Isto é, uma percepção sobre as diferenças sexuais, as quais são hierarquizadas dentro de um sistema de pensamento engessado e dual. É evidente que as diferenças sexuais existem, ou seja, que os corpos sexuados apresentam diferenças entre 
si. O problema está no fato de que se constroem significados culturais para essas diferenças, o que é feito invariavelmente de modo hierárquico. E é por isso que não se deve pensar o sexo como um produto da natureza, até mesmo porque a cisão entre cultura e natureza é um efeito cultural. Ademais, o gênero não está somente na personalidade e no comportamento dos sujeitos, mas no corpo e no modo como ele aparece. Isso significa que o sexo não pode ser totalmente independente do gênero. Ambos são saberes, de modo que não se deve associar exclusivamente o primeiro à natureza e o segundo à cultura, sob pena de se incorrer novamente no erro de perpetuar a noção de sexo como a-histórico e pré-discursivo (ButLer, 2016).

Nessa perspectiva, é possível compreender o motivo pelo qual o gênero e o sexo se colocam quase que como debates anteriores ao próprio sujeito. Em uma entrevista destinada a debater o sexo e a política da identidade, Foucault (2004) problematiza esta última categoria quando tomada em uma acepção limitadora e castradora do ser e das possibilidades. Inclusive no que diz respeito às perspectivas não convencionais de gênero, Foucault (2004, p. 265-266) assevera que

se a identidade é apenas um jogo, apenas um procedimento para favorecer relações, relações sociais e as relações de prazer sexual que criem novas amizades, então ela é útil. Mas se a identidade se torna o problema mais importante da existência sexual, se as pessoas pensam que elas devem "desvendar" sua "identidade própria" e que esta identidade deva tornar-se a lei, o princípio, o código de sua existência, se a questão que se coloca continuamente é: "Isso está de acordo com minha identidade?”, então eu penso que fizeram um retorno a uma forma de ética muito próxima à da heterossexualidade tradicional.

De fato, há um modelo social compulsório que torna o ser inteligível somente na medida em que adquire um gênero que, por sua vez, deve ser também inteligível. "Gêneros 'inteligíveis' são aqueles que, em certo sentido, instituem e mantêm relações de coerência e 
continuidade entre sexo, gênero, prática sexual e desejo." (ButLer, 2016, p. 43). Ao fim e ao cabo, a mulher performa a feminilidade e o homem a masculinidade em processos de subjetivação, ainda que sobremaneira inconscientes. Não surpreende, portanto, que os papéis de gênero, quando exercidos nos termos de uma ordem compulsória, tragam consequências danosas para o self tanto de homens quanto de mulheres, limitando as possibilidades dos sujeitos e dos corpos e impondo, muitas vezes, uma vida de sofrimento diante da necessidade do enquadramento imprescindível à aceitação social. É o caso da travesti, do(a) transexual, do(a) transgênero(a) e dos(as) andróginos(as) que - ao contrário do cisgênero (pessoa que se identifica com as características de gênero que lhe foram atribuídas quando do nascimento, levando em consideração especialmente o órgão sexual) - (re)inventam seus corpos em busca de uma identidade alheia às convenções impostas ao seu sexo e gênero.

Não é possível prosseguir sem deixar de mencionar o desconforto que causam ditas classificações, pois se nomear implica, por um lado, visibilizar pela via do que se expressa, do que se diz; por outro, sectariza, classifica e coloca determinados grupos sob o olhar vigilante e disciplinar típico dos discursos científicos. Nesse prisma, é importante mencionar que a transexualidade, a transgeneridade e a travestilidade são termos polissêmicos, fluídos e passíveis de ressignificação constante pelos sujeitos, dependendo do contexto e das experiências singulares de cada um (Longaray; Ribeiro, 2016).

Finalmente, um terceiro ponto importante é a orientação sexual. Em linhas gerais, a orientação sexual do sujeito é determinada a partir da constatação de que ele tem seu desejo direcionado/orientado para parceiros do mesmo sexo (homossexualidade), de sexo distinto (heterossexualidade) ou para ambos os sexos (bissexualidade). Além disso, recentemente a condição de pansexual tem recebido destaque. $\mathrm{O}$ conceito, ainda bastante recente (e, portanto, controverso), parece remeter aos sujeitos que questionam a binariedade dos sexos, de modo que se interessam, simplesmente, por indivíduos. 
Com isso, resta evidente que reduzir a análise do gênero a características meramente físicas é no mínimo ineficaz, para não dizer violador de liberdades fundamentais. Ora, se a identidade de gênero, como visto, diz do sujeito numa perspectiva centrífuga, ou seja, parte do indivíduo para a sociedade, e não o contrário, não há qualquer razão de ordem jurídico-normativa a autorizar que, num Estado democrático de Direito, a sociedade imponha a identificação de gênero do ser humano.

Feito esse aparte, necessário para evitar o grave equívoco de confundir sobretudo categorias como identidade de gênero e orientação sexual, passa-se à análise da OC 24/07 da Corte Interamericana, bem como de seu importante eco nos autos da ADI 4275/DF, especialmente no voto da lavra do Ministro Luiz Edson Fachin, Redator do acórdão.

\section{OC 24/17 E ADI 4275/DF: 0 DIÁLOGO DAS CORTES É POSSÍVEL?}

Comecemos pela OC 24/17, de 24 de novembro de 2017, resultado de uma solicitação feita pelo Estado da Costa Rica em maio de 2016. Da consulta, participaram especialistas das mais diversas áreas, associações internacionais e nacionais, instituições acadêmicas, organizações não governamentais e juristas de renome como Pablo Stolze, docente da Universidade Federal da Bahia. Destaca-se, também, a atuação das Defensorias Públicas da União e do Estado do Rio de Janeiro.

O Estado da Costa Rica basicamente formulou cinco perguntas de temas relacionados às pessoas LGBTI, as quais podem ser sintetizadas nos seguintes termos:

1. "Tomando en cuenta que la identidad de género es una categoría protegida por los artículos 1 y 24 de la CADH, además de lo establecido en los numerales 11.2 y 18 de la Convención ¿contempla esa protección y la CADH que el Estado deba reconocer y facilitar el cambio de nombre de las personas, de acuerdo con la identidad de género de cada una?"; 
2. "En caso que la respuesta a la anterior consulta fuera afirmativa, ¿se podría considerar contrario a la CADH que la persona interesada en modificar su nombre de pila solamente pueda acudir a un proceso jurisdiccional sin que exista un procedimiento para ello en vía administrativa?";

3. “¿Podría entenderse que el artículo 54 del Código Civil de Costa Rica, debe ser interpretado, de acuerdo con la CADH, en el sentido de que las personas que deseen cambiar su nombre de pila a partir de su identidad de género no están obligadas a someterse al proceso jurisdiccional allí contemplado, sino que el Estado debe proveerles un trámite administrativo gratuito, rápido y accesible para ejercer ese derecho humano?";

4. "Tomando en cuenta que la no discriminación por motivos de orientación sexual es una categoría protegida por los artículos 1 y 24 de la CADH, además de lo establecido en el numeral 11.2 de la Convención ¿contempla esa protección y la CADH que el Estado reconozca todos los derechos patrimoniales que se derivan de un vínculo entre personas del mismo sexo?", y 5. "En caso que la respuesta anterior sea afirmativa, ¿es necesaria la existencia de una figura jurídica que regule los vínculos entre personas del mismo sexo, para que el Estado reconozca todos los derechos patrimoniales que se derivan de esta relación?" (CORTE IDH, 2017b, p. 01).

O questionamento mais afinado com o tema aqui discutido e que vai reverberar de modo muito especial na ADI 4275/DF é aquele constante do $\mathrm{n}^{\mathrm{o}} \mathrm{s} 01 \mathrm{a} 03$, porquanto se referem especialmente à identidade de gênero, ao passo em que os questionamentos subsequentes tratam notadamente da orientação sexual. Portanto, centremo-nos naqueles três primeiros pontos. Especificamente no tocante aos princípios da igualdade e da não discriminação, a Corte reiterou que, de acordo com as garantias do artigo 1.1 da Convenção Americana, a orientação sexual e a identidade de gênero, assim como a expressão de gênero, são categorias protegidas pela Convenção Americana de Direitos Humanos. Consequência disso é que nenhuma norma, decisão ou prática do direito interno, seja por autoridades de Estado ou por 
particulares pode restringir ou minimizar os direitos de uma pessoa em razão de sua orientação sexual, de sua identidade de gênero ou de sua expressão de gênero.

Quanto à identidade de gênero, a Corte também adverte que essa categoria diz respeito unicamente à identidade autopercebida que o sujeito tem sobre si próprio, o que não significa, obviamente, que a identidade não seja construída e conformada coletivamente. Para a Corte, isso implica que o reconhecimento da identidade de gênero se encontra ligado necessariamente à ideia de que o sexo e o gênero devem ser percebidos como partes integrantes de um processo extremamente complexo de construção identitária e de subjetividade, resultando antes da decisão livre e autônoma de cada sujeito, não estando condicionada ou subordinada, portanto, à genitalidade.

A Corte também asseverou que a identidade de gênero é um elemento constitutivo e constituinte da identidade das pessoas, de modo que seu reconhecimento por parte do Estado é de vital importância para garantir o pleno gozo de direitos humanos de pessoas transgênero, seja do ponto de vista dos direitos civis e políticos, seja do ponto de vista dos direitos econômicos, sociais e culturais.

No tocante especificamente ao direito ao reconhecimento à personalidade jurídica, ao direito ao nome e ao direito à identidade de gênero (temas centrais posteriormente debatidos na ADI 4275/DF), a Corte expressou que o livre desenvolvimento da personalidade e o direito à vida privada e à intimidade acarretam necessariamente o reconhecimento de direitos da identidade pessoal, sexual e de gênero. É que é justamente a partir de tais categorias que a pessoa se projeta frente a si mesmo e frente à coletividade. $\mathrm{O}$ nome, como atributo da personalidade, é uma das mais importantes expressões da individualidade, fazendo com que cada pessoa possua um signo distintivo e singular frente aos demais. É, diz a Corte, direito fundamental inerente a todas as pessoas pelo simples fato de sua existência. Com base nisso, o Tribunal argumentou que o direito de cada pessoa de definir autonomamente sua identidade sexual e de gênero, bem como 
o direito a tais registros e documentos de identidade, são protegidos pela Convenção Americana através das disposições que garantem o livre desenvolvimento da personalidade (artigos 7 e 11.2), o direito à privacidade (artigo 11.2), o reconhecimento da personalidade jurídica (artigo 3) e, finalmente, o direito ao nome (artigo 18).

Isso significa que os Estados devem respeitar e garantir a toda pessoa a possibilidade de registrar e inclusive mudar, retificar ou adequar o seu nome e os demais componentes essenciais de sua identidade, a exemplo da imagem, da referência ao sexo ou gênero, independentemente de quaisquer interferências por parte de autoridades públicas ou terceiros. Por isso, as pessoas que se identificam com identidades de gênero diversas devem ser reconhecidas do modo como queiram, o que significa que o Estado deve garantir a tais grupos o exercício desse direito tão elementar. Portanto, em resposta à primeira pergunta formulada pela Costa Rica, a Corte concluiu que a mudança de nome, a adequação da imagem e a retificação do sexo ou gênero nos registros e nos documentos de identificação, a fim de que fiquem conformes à identidade de gênero autopercebida pelo sujeito, é um direito protegido pelo artigo 18 da Convenção (direito ao nome) e também pelos artigos 3 (reconhecimento da personalidade jurídica), 7.1 (liberdade) e 11.2 (direito à vida privada), todos da Convenção Americana de Direitos Humanos.

Sobre os procedimentos para troca de nome e demais informações de identificação em virtude de identidade de gênero, também são dignas de congratulações as considerações da Corte, para quem os Estados podem estabelecer e decidir qual o procedimento mais adequado, levando em consideração cada contexto fático e seu direito interno para troca de nome, adequação da imagem e retificação da referência ao sexo ou gênero no registro civil e nos documentos de identificação, desde que seja considerada a identidade de gênero autopercebida. Independentemente da escolha do Estado pelo procedimento jurisdicional ou administrativo, no entanto, devem ser cumpridas as seguintes condições: a) tais procedimentos devem estar 
exclusivamente alicerçados na identidade de gênero autopercebida pelo sujeito; b) devem ter por base unicamente o consentimento livre e informado do solicitante, sem que se exijam certificações médicas, psicológicas, psiquiátricas etc. ou outras que possam resultar desarrazoadas e patologizantes; c) devem ser confidenciais e não podem fazer menção ao fato de que decorreram de alteração para se adequar à identidade de gênero; d) devem ser, na medida do possível, gratuitos; e, por fim, e) não devem ser exigidas quaisquer espécies de operação cirúrgica ou tratamento hormonal. A Corte assinalou, finalmente, que os trâmites de natureza administrativa ou notarial são os que melhor se ajustam e se adequam a tais requisitos.

Por fim, os juízes também acordaram que a regulação do procedimento de troca de nome, de adequação da imagem ou de retificação de referência ao sexo ou gênero nos registros e documentos de identidade não necessariamente deve ser regulado por lei específica, na medida em que deve consistir única a exclusivamente num procedimento simples de verificação da manifestação livre e voluntária do requerente.

Quanto ao artigo 54 do Código Civil da Costa Rica, que consagra um procedimento de jurisdição voluntária para alteração do nome, a Corte advertiu que, em sua redação atual, esse dispositivo legal somente é compatível com as disposições da Convenção Americana se for interpretado no sentido do que decidido pela Corte quanto aos questionamentos anteriores, especificamente no que se refere ao cumprimento das condições mencionadas anteriormente. Logo, o artigo 54 do Código Civil da Costa Rica deve ser interpretado de acordo com os parâmetros previamente estabelecidos para que pessoas que desejem adequar integralmente os registros e/ou os documentos de identidade à sua identidade de gênero autopercebida possam gozar efetivamente desse direito humano tão elementar reconhecido nos artigos 3, 7, 11.2, 13 e 18 da Convenção Americana.

Finalmente, no tocante às duas últimas perguntas formuladas pelo Estado da Costa Rica relativamente à orientação sexual ser uma 
categoria protegida pelos artigos 1 e 24 da CADH e à obrigatoriedade dos Estados de reconhecer os direitos patrimoniais que derivarem do vínculo entre pessoas do mesmo sexo, a Corte aduziu que o Pacto de San José protege o vínculo familiar que possa surgir de uma relação de um casal do mesmo sexo, com base no artigo 11.2 e 17 daquele instrumento legal. Com isso, mencionou que devem ser protegidos, sem discriminação alguma, todos os direitos patrimoniais que derivem deste vínculo familiar. Ainda no tocante à orientação sexual, mas agora quanto ao último questionamento, a Corte asseverou que pode ser necessário que os Estados modifiquem figuras existentes em seus ordenamentos através de medidas legislativas, judiciais ou administrativas para estendê-las aos casais formados por pessoas do mesmo sexo.

A análise que aqui se pretendeu não teve por objetivo esgotar o tema e todos os melindres da OC, até mesmo porque ela conta com 145 páginas que abordam as entrelinhas da temática de maneira extremamente ousada, inclusive se compararmos a postura da Corte Interamericana com outras Cortes internacionais. Mas um último ponto extremamente controverso a ser abordado no tocante à OC 24/17 é aquele em torno da natureza jurídica que assumem tais pareceres no tocante à coercitividade dos Estados-membros. Há no Direito Internacional dos Direitos Humanos um debate bastante acalorado sobre se os pareceres emanados pela Corte no exercício de sua função consultiva são vinculantes ou meras recomendações. O chileno Héctor Faúndez Ledesma (2004, p. 990), nesse sentido, expressamente adverte que

sería absurdo que cada uno de los Estados partes pudiera interpretar la Convención a su arbitrio o de la manera que le pareciera, absolutamente sin ningún control; es por eso que, en caso de dudas en cuanto al sentido y alcance de sus disposiciones, se ha señalado cuál es el órgano encargado de emitir un pronunciamiento sobre la interpretación correcta de las mismas pero, por supuesto, esa interpretación es vinculante para los Estados y no puede constituir una mera 'opinión'. Por consiguiente, no podemos compartir una tesis que disminuye el valor de los dictámenes de la Corte, 
y que parece estar en contradicción con la definición que el propio tribunal ha proporcionado de su competencia consultiva, señalando que ésta constituye "un método judicial alterno de carácter consultivo”; de manera que, más allá de la conveniencia y de la utilidad práctica de la jurisdicción consultiva, consideramos que una correcta interpretación de la Convención requiere, en esta materia, hacer algunas distinciones preliminares, cuya importancia la Corte no parece haber percibido.

Esse posicionamento, defendendo que as opiniões consultivas emitidas pela Corte são vinculantes, vem se fortalecendo cada vez mais na jurisprudência internacional.

Passemos agora ao breve estudo da ADI 4275/DF, ajuizada perante o STF pela Procuradoria-Geral da República (PGR) em 21/07/2009, em face da redação do artigo 58 da Lei de Registros Públicos (Lei n ${ }^{\circ}$ 6.015/1973). O julgamento da ação, realizado em março de 2018, que ao final foi tida como procedente por maioria de votos para o fim de dar interpretação conforme a Constituição e o Pacto de São José da Costa Rica ao dispositivo legal em questão, restou assim ementado:

AÇÃO DIRETA DE INCONSTITUCIONALIDADE. DIREITO CONSTITUCIONAL E REGISTRAL. PESSOA TRANSGÊNERO. ALTERAÇÃO DO PRENOME E DO SEXO NO REGISTRO CIVIL. POSSIBILIDADE. DIREITO AO NOME, AO RECONHECIMENTO DA PERSONALIDADE JURÍDICA, À LIBERDADE PESSOAL, À HONRA E À DIGNIDADE. INEXIGIBILIDADE DE CIRURGIA DE TRANSGENITALIZAÇÃO OU DA REALIZAÇÃO DE TRATAMENTOS HORMONAIS OU PATOLOGIZANTES. 1. O direito à igualdade sem discriminações abrange a identidade ou expressão de gênero. 2 . A identidade de gênero é manifestação da própria personalidade da pessoa humana e, como tal, cabe ao Estado apenas o papel de reconhecê-la, nunca de constituí-la. 3. A pessoa transgênero que comprove sua identidade de gênero dissonante daquela 
que lhe foi designada ao nascer por autoidentificação firmada em declaração escrita desta sua vontade dispõe do direito fundamental subjetivo à alteração do prenome e da classificação de gênero no registro civil pela via administrativa ou judicial, independentemente de procedimento cirúrgico e laudos de terceiros, por se tratar de tema relativo ao direito fundamental ao livre desenvolvimento da personalidade. 4. Ação direta julgada procedente. (ADI 4275, Relator: Min. Marco Aurélio, Relator p/ Acórdão: Min. Edson Fachin, Tribunal Pleno, julgado em 01/03/2018, Publicado em 07/03/2019).

O caput do artigo 58 da Lei de Registros Públicos preceitua que "o prenome será definitivo, admitindo-se, todavia, a sua substituição por apelidos públicos notórios." De acordo com a PGR a interpretação desse preceito em consonância com os artigos $1^{\circ}$, inciso III, $3^{\circ}$, inciso IV, e $5^{\circ}$, caput e inciso X, da Constituição Federal de 1988 direciona à possibilidade de mudança de sexo e prenome, por transexuais, no registro civil. Assevera a PGR, em linhas gerais, que o direito fundamental à identidade de gênero justifica a troca de prenome, independentemente da realização da cirurgia. Argui, ainda, mostrar-se consentânea com a Magna Carta a interpretação segundo a qual a expressão "apelidos públicos notórios", inserida no caput do artigo 58 da Lei $\mathrm{n}^{\circ}$ 6.015/1973, abrange o prenome social dos transexuais, ensejando também a modificação relativa ao registro de gênero. Com base nisso, requereu fosse conferida interpretação conforme à Constituição Federal ao artigo 58 da Lei no 6.015/1973, reconhecendo-se aos transexuais, independentemente da realização de cirurgia de transgenitalização, o direito à mudança de prenome e sexo no registro civil. Pede, caso o indivíduo não opte pela cirurgia, a fixação dos seguintes requisitos para a alteração do assentamento: (i) idade superior a 18 anos; (ii) convicção, há pelo menos 3 anos, de pertencer ao gênero oposto ao biológico; e (iii) baixa probabilidade, de acordo com pronunciamento de grupo de especialistas, de modificação da identidade de gênero (Brasıl, 2018, p. 06). 
Veja-se que aqui a ADI já apresenta algumas incongruências conceituais desde o princípio, pois o pedido da PGR foi formulado com base na identidade "transexual", quando deveria ter levado em consideração, também (e sobretudo) as pessoas transgêneras. É que, a expressão "transgênero" é utilizada para incluir em um só termo transexuais, travestis e outras formas de identidade de gênero, como pessoas não binárias, por exemplo. Já o transexual costuma ter um sentimento de não pertencer ao seu gênero biológico a tal ponto que rechaça veementemente aquilo que é característica do seu sexo de nascimento, inclusive e especialmente sua genitália ${ }^{1}$. Não existe uniformidade científica quanto aos conceitos de transexual e transgênero e às suas diferenças, mas para fins didáticos, é possível resumir que a pessoa transgênera não sente a necessidade de mudar sua anatomia, em que pese se expresse e deseje ser reconhecida como sendo do sexo oposto. Já a pessoa transexual quer poder se expressar e ser reconhecida como sendo do sexo oposto, desejando, outrossim, modificar sua anatomia por terapia hormonal e/ou cirurgia de redesignação sexual.

É evidente que em alguns casos a pessoa transexual "opta” por não fazer a cirurgia de transgenitalização, e isso deve-se a uma imensa gama de fatores que perpassam desde condições patológicas, como as coagulopatias, até questões de cunho financeiro e geográfico que nada têm de opcional, até mesmo porque hoje, dos nove hospitais habilitados pelo Ministério da Saúde, apenas cinco hospitais realizam o procedimento cirúrgico pelo Sistema Único de Saúde.

Essa situação de descuidado conceitual fica evidente no voto proferido pelo Ministro Marco Aurélio Melo: "Presidente, apenas

Exemplo de transexualidade pode ser vista no caso Luiza Melinho vs. Brasil, atualmente aguardando análise de fundo da Comissão Interamericana de Direitos Humanos. A impossibilidade de realização das cirurgia de redesignação sexual fez com que, Luiza Melinho, já esgotada psicologicamente, mutilasse seus próprios genitais em um ato de verdadeiro desespero (CIDH, 2016, p. 02, \$10). 
um esclarecimento. Quando versei transexuais - não mergulhei, até mesmo para estabelecer a diferença, nas definições de transexuais e transgêneros -, o fiz considerado o pedido formalizado na inicial da ação direta de inconstitucionalidade. E esse pedido é explícito, diz respeito apenas aos transexuais." (Brasil, 2018, p. 41). Diante disso, o Ministro Edson Fachin faz um aparte e sugere, justamente com base na OC 24/17, que se utilize o termo transgênero em detrimento de transexual (BrasiL, 2018).

O voto do Ministro Luiz Edson Fachin possivelmente seja, dentre todos, o mais completo tecnicamente falando e afinado com a noção de direitos humanos, motivo pelo qual centramos nossa análise em suas palavras. O Ministro Redator do acórdão partiu de três premissas: a) o direito à igualdade sem discriminações abrange a identidade ou expressão de gênero. Ou seja, o respeito à identidade de gênero é uma decorrência do princípio da igualdade; b) a identidade de gênero é manifestação da própria personalidade da pessoa humana (como fruto de um autorreconhecimento) e, como tal, cabe ao Estado apenas o papel de reconhecê-la, nunca de constituí-la; e c) a pessoa não deve provar o que é e o Estado não deve condicionar a expressão da identidade a qualquer tipo de modelo, ainda que meramente procedimental (Brasil, 2018, p. 24).

Fachin, em um verdadeiro diálogo das Cortes pontua as bases constitucionais (direito à intimidade, à vida privada, à honra e à imagem, do art. $5^{\circ}, \mathrm{X}$, da CRFB) e convencionais da matéria em discussão. Quanto à convencionalidade, traz à luz o artigo $5^{\circ}, \mathbb{S} 2^{\circ}$, segundo o qual "os direitos e garantias expressos nesta Constituição não excluem outros decorrentes do regime e dos princípios por ela adotados, ou dos tratados internacionais em que a República Federativa do Brasil seja parte." Ainda, pontua a importância do direito ao nome (artigo 18 do Pacto de São José da Costa Rica), do direito ao reconhecimento da personalidade jurídica (artigo 3 do Pacto), do direito à liberdade pessoal (artigo 7.1 do Pacto) e do direito à honra e à dignidade (artigo 11.2 do Pacto). 
O Ministro, assim como fizeram Rosa Weber e Luis Roberto Barroso, mencionou em seu voto a importância da OC 24/17 da Corte Interamericana, usando-a claramente como um norte interpretativo para conduzir todo o seu voto, especialmente para o fim de definir que não deve ser exigido o procedimento jurisdicional (nem mesmo de jurisdição voluntária) para a mudança de nome e de outras informações constantes do registro civil da pessoa.

Nesse mesmo sentido, em defesa da prescindibilidade do procedimento jurisdicional, o Ministro Luis Roberto Barroso (BRASIL, 2018, p. 54) aduz que

nós precisamos ter em conta também que o mundo do Direito, da judicialização, é muito simples para nós que vivemos nele, que falamos essa língua difícil, que usamos essas roupas, mas para as pessoas mais humildes, às vezes em lugares distantes, a necessidade de ir ao Poder Judiciário pode ser um obstáculo insuperável, ou pode ser um constrangimento a mais.

Assim como não existiu a pretensão de exaurir a OC 24/17, também não podemos fazê-lo com relação à ADI 4275. De qualquer maneira, este belo julgamento de 173 páginas evidencia um grupo de julgadores entusiasmados com a temática e preocupados em estabelecer um decisum que esteja de acordo com os preceitos internacionais protetivos de direitos humanos.

Ao final, o julgamento da ADI foi no sentido de que o transgênero tem direito fundamental subjetivo à alteração de seu prenome e de sua classificação de gênero no registro civil, não se exigindo, para tanto, nada além da manifestação de vontade do indivíduo, faculdade que pode ser exercida tanto pela via judicial, como pela administrativa. Essa alteração, é bom dizer, será averbada à margem do assento de nascimento, vedando-se expressamente a inclusão do termo "transgênero". Em outras palavras, a pessoa transgênera que comprove sua identidade de gênero dissonante daquela que lhe foi designada no nascimento, fazendo-o por autoidentificação firmada em declaração 
escrita, tem direito subjetivo à alteração do prenome e da classificação de gênero no registro civil, seja administrativa ou judicialmente e, é bom dizer, independentemente de quaisquer procedimentos cirúrgicos, tratamentos e laudos de terceiros.

O fato é que quase meio século após o início das discussões envolvendo a identidade de gênero e a sexualidade, os resultados são, não se pode negar, animadores. Por outro lado, o retrocesso é um risco sempre presente e potente em se tratando de direitos humanos. Basta pensar que na ADI 4275/DF, por exemplo, a Câmara dos Deputados, intimada para se manifestar sobre a demanda, disse, por meio de seu Presidente, não ter informações a respeito. O Senado Federal, por outro lado, opinou pela total improcedência do pedido. Em uma visão totalmente retrógrada e violadora do direito à esfera privada, consignou ser mais razoável "viabilizar a alteração do prenome e do sexo civil tão somente aos transexuais redesignados." (Brasil, 2018, p. 18).

Isso justifica, em boa medida, o motivo pelo qual a proteção efetiva de direitos humanos tem sido encabeçada, em muitos países latino-americanos, não pelo Poder Legislativo (por meio de atos normativos) ou pelo Executivo (com políticas públicas eficazes), mas pelo Poder Judiciário.

Outro grande entrave à concretização dos direitos aqui enunciados reside na seguinte pergunta: "por que é tão mais fácil declarar a liberdade sexual de forma negativa, e não em um sentido positivo e emancipatório?" (Petchesky, 1999, p. 24). Por que temos mais facilidade de formar um consenso sobre estupro, casamento forçado, escravidão, mutilação genital e outras formas de violência sexual, mas não sobre o direito de usufruir plenamente do seu próprio corpo e da própria subjetividade? Não se desconhece que o problema da construção negativa dos direitos sexuais integra o debate sobre os direitos humanos. Nem que as dimensões negativa e positiva da sexualidade se interligam de modo dialético. É evidente que tais categorias devem estar representadas na norma a partir da (i)licitude, mas o fato é que 
a ênfase dada a estes casos estandardiza (e coloniza) o sujeito erótico que integra uma minoria sexual.

Mas por que nos sensibilizamos com o terror, com o drama, com a dor e o sofrimento alheios e, por outro lado, nos mantemos tão indiferentes ao fato de que muitas pessoas passam pela vida tendo experimentado uma sexualidade frustrada, castrada, opressora? Um gênero com o qual não se identificam? Um gênero que não são?

Como uma categoria que tenta ser inclusiva e universal, os direitos sexuais podem cometer o mesmo erro experimentado pela ideia de direitos humanos na Modernidade de tornarem-se uma linguagem totalizante e excludente, que mais obscurece do que visibiliza (visibilizando somente quando e quem convém). Então, de que modo criar uma estrutura geral de direitos sexuais que inclua toda a imensa gama de especificidades próprias de cada indivíduo? Com efeito, embora falemos cada vez mais sobre o sexo, conforme já ponderava Foucault (1979), o fazemos inadequadamente, por meio de um discurso sempre transbordado da culpa judaico-cristã da qual somos verdadeiros cúmplices e reprodutores e da qual agora devemos nos libertar.

\section{CONCLUSÃO}

Com efeito, apesar dos inúmeros avanços encabeçados pelos movimentos feminista, gay, lésbico, trans e de profissionais do sexo, ainda há um longo caminho a ser percorrido para que a inserção de tais grupos na vida social efetivamente se verifique do ponto de vista da cidadania e instrumentos legais e políticas públicas a eles relativos surjam de forma abrangente em domínios importantes e efetivos nos Estados. Enquanto isso, o Poder Judiciário, seja no âmbito local, seja no internacional, vem se mostrando como um grande aliado de tais grupos quando da tomada de decisões que são, infelizmente, contramajoritárias, mas fundamentais à concretização dos direitos mais elementares de determinadas identidades vulnerabilizadas. 
Após este breve estudo, foi possível perceber que se temos problemas no cenário latino-americano relativamente aos chamados DESC, não se pode negar que os direitos de primeira geração ainda caminham a passos lentos rumo à sua consolidação. Basta ter em mente que falamos, aqui, do nome, tão elementar direito da personalidade, veementemente negado a determinados sujeitos por motivos absolutamente banais e que desinteressam à esfera pública.

Diante do exposto, não se pode negar que apesar das suas limitações fáticas - dentre as quais as mais gravosas talvez digam respeito às questões de cunho orçamentário e ao descumprimento das recomendações e decisões pelos Estados-membros - o Sistema Interamericano tem tentado agir com aquilo que está ao seu alcance, apreciando as demandas, inclusive relacionadas à sexualidade e à identidade de gênero, em conformidade com a noção de direitos humanos e de respeito à diversidade.

Sendo assim, apesar da falta de um instrumento legislativo vinculante (ao menos assim concebido de forma unânime) destinado à tutela da sexualidade e da identidade de gênero no âmbito da OEA, o fato é que o SIDH funciona como um importante mecanismo de proteção de direitos humanos, sinalizando, com suas importantes decisões e pareceres, para uma mudança de paradigma em termos de justiça de gênero e de sexualidade no cenário internacional, cuja repercussão, conforme demonstrado, tem sido profícua também no cenário nacional, especialmente após o julgamento da ADI 4275/DF, evidenciando um possível e fecundo diálogo das Cortes.

\section{REFERÊNCIAS}

BATAILLE, Georges. O erotismo. Tradução de Fernando Scheibe. Belo Horizonte: Autêntica Ed., 2014.

BEAUVOIR, Simone de. O segundo sexo. Tradução de Sérgio Milliet. 2. ed. 2. v. Rio de Janeiro: Nova Fronteira, 2009. 
BRASIL. Supremo Tribunal Federal. ADI 4275/DF, julgada em 8 fev. e 1 mar. 2018. Requerente: Procuradoria-Geral da República. Relator: Ministro Marco Aurélio. Redator do Acórdão: Ministro Edson Fachin. Brasília, 01 mar. 2019. Disponível em: http://portal.stf.jus.br/processos/downloadPeca. asp?id=15339649246\&ext $=$.pdf. Acesso em: 28 set. 2019.

BUTLER, Judith. Problemas de gênero: feminismo e subversão da identidade. Tradução de Renato Aguiar. 10. ed. Rio de Janeiro: Civilização Brasileira, 2016.

COMISSÃO INTERAMERICANA DE DIREITOS HUMANOS (CIDH). Avances y desafíos hacia el reconocimiento de los derechos de las personas LGBTI en las Américas, 2018. Disponível em: http://www. oas.org/es/cidh/informes/pdfs/LGBTI-ReconocimientoDerechos2019.pdf. Acesso em: 14 set. 2019.

COMISSÃO INTERAMERICANA DE DIREITOS HUMANOS (CIDH). Informe no 11/16, Petição no 362-09. Admissibilidade. Luiza Melinho vs. Brasil. 14 abr. 2016. Disponível em: http://www.oas.org/es/ cidh/decisiones/2016/BRAD362-09ES.pdf. Acesso em: 28 set. 2019.

COMISSÃO INTERAMERICANA DE DIREITOS HUMANOS (CIDH). Violência contra pessoas lésbicas, gays, bissexuais, e intersexo nas Américas, 2015a. Disponível em: http://www.oas.org/pt/cidh/docs/ pdf/ViolenciaPessoasLGBTI.pdf. Acesso em: 07 nov. 2018.

CORTE INTERAMERICANA DE DIREITOS HUMANOS. Opinião Consultiva $n^{\circ}$ 24/17 (OC no 24/17). 24 nov. 2017. Disponível em: http://www.corteidh.or.cr/docs/opiniones/seriea_24_esp.pdf. Acesso em: 22 jul. 2018.

CORTE INTERAMERICANA DE DIREITOS HUMANOS. Opinião Consultiva $n^{\circ}$ 24/17 (Resumen oficial). 24 nov. 2017b. http://www.corteidh.or.cr/docs/opiniones/resumen_seriea_24_esp.pdf

FAÚNDEZ LEDESMA, Héctor. El sistema interamericano de protección de los derechos humanos: aspectos institucionales y procesales. San José, Costa Rica: Instituto Interamericano de Derechos Humanos, 2004.

FOUCAULT, Michel. A arqueologia do saber. Tradução de Luiz Felipe Baeta Neves. Rio de Janeiro: Forense Universitária, 2008.

FOUCAULT, Michel. História da sexualidade I: a vontade de saber. 22. impr. Rio de Janeiro: Ed. Graal, 2012. 
FOUCAULT, Michel. Microfísica do poder. Tradução de Roberto Machado. Rio de Janeiro: Ed. Graal, 1979.

LONGARAY, Deise Azevedo; RIBEIRO, Paula Regina Costa. Travestis e transexuais: corpos (trans)formados e produção da feminilidade. Estudos Feministas, Florianópolis, v. 24, n. 3, p. 761-784, set. 2016. Disponível em: https://periodicos.ufsc.br/index.php/ref/article/view/46748/32493. Acesso em: 13 jul. 2017.

LUCAS, Doglas Cesar; CENCI, Ana Righi. A identidade latino-americana como problema e a necessidade de uma proposta intercultural. In: SANTOS, André Leonardo Copetti; LUCAS; Doglas Cesar; BRAGATO, Fernanda Frizzo (Orgs.). Pós-colonialismo, pensamento descolonial e direitos humanos na América Latina. Santo Ângelo: FURI, 2015. p. 85-100.

ORGANIZAÇÃO DOS ESTADOS AMERICANOS (OEA). Carta da Organização dos Estados Americanos, 13 dez. 1951. Disponível em: http:// www.dhnet.org.br/direitos/anthist/marcos/hdh_carta_oea_1948.pdf. Acesso em: 15 nov. 2016.

ORGANIZAÇÃO DOS ESTADOS AMERICANOS (OEA). Convenção Americana de Direitos Humanos (Pacto de San José da Costa Rica), adotada em 22 de novembro de 1969. Disponível em: https://www.cidh.oas.org/ basicos/portugues/c.convencao_americana.htm. Acesso em: 15 nov. 2016. ORGANIZAÇÃO DOS ESTADOS AMERICANOS (OEA). Declaração Americana dos Direitos e Deveres do Homem, abr. 1948. Disponível em: https://www.cidh.oas.org/basicos/portugues/b.Declaracao_Americana. htm. Acesso em: 16 jun. 2017.

ORGANIZAÇÃO DOS ESTADOS AMERICANOS (OEA). Protocolo Adicional à Convenção Americana sobre Direitos Humanos em Matéria de Direitos Econômicos, Sociais e Culturais (Protocolo de San Salvador), 17 nov. 1988. Disponível em: https://www.cidh.oas.org/basicos/ portugues/e.Protocolo_de_San_Salvador.htm. Acesso em: 16 jun. 2017.

PETCHESKY, Rosalind Pollack. Direitos sexuais: um novo conceito na prática política internacional. In: BARBOSA, Regina Maria; PARKER, Richard (Orgs.). Sexualidades pelo avesso. Rio de Janeiro: IMS/UERJ, 1999. p. 15-38. PIOVESAN, Flávia. Direitos humanos e justiça internacional: um estudo comparativo dos sistemas regionais europeu, interamericano e africano. São Paulo: Saraiva, 2006. 
PRINCÍPIOS DE Yogyakarta. Princípios sobre a aplicação da legislação internacional de direitos humanos em relação à orientação sexual e identidade de gênero, 2007. Disponível em: <http://www.clam.org.br/ uploads/conteudo/principios_de_yogyakarta.pdf >. Acesso em: 15 jul. 2017. SCOTT, Joan. Gênero: uma categoria útil para análise histórica. Tradução de Christiane Rufino Dabat e Maria Betânia Ávila. New York: Columbia University Press, 1989.

STRECK, Lenio Luiz. Hermenêutica jurídica e(m) crise: uma exploração hermenêutica da construção do Direito. 11. ed. rev., atual. e ampl. Porto Alegre: Livraria do Advogado, 2014.

ZAFFARONI, Eugenio Raúl. La historia de los derechos humanos en América Latina. In: OLGUÍN; Leticia (Org.). Educación y derechos humanos: una discusión interdisciplinaria. São José da Costa Rica: Instituto Interamericano de Derechos Humanos, 1989, p. 21-80, p. 22.

\section{PÂMELA COPETTI GHISLENI}

Mestre em Direito, com ênfase em Direitos Humanos, pelo Programa de Pós-Graduação Stricto Sensu em Direito da Universidade Regional do Noroeste do Estado do Rio Grande do Sul - UNIJUÍ.

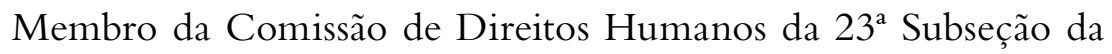
OAB/RS, Advogada (OAB/RS 100.497) e Professora no Curso de Graduação em Direito da Faculdade CNEC Santo Ângelo/RS. Endereço profissional: Rua Professor Dr. João Augusto Rodrigues, 471 - Harmonia, Santo Ângelo - RS, 98801-015 - Faculdade CNEC Santo Ângelo, Brasil.

ORCID ID: https://orcid.org/0000-0003-0166-9462

E-MAIL: 1432.pamelaghisleni@cnec.br; pcghisleni@gmail.com

\section{DOGLAS CESAR LUCAS}

Mestre em Direito pela UFSC, Doutor em Direito pela UNISINOS e Pós-Doutor em Direito pela Università Degli Studi di Roma 
Tre. Professor dos Cursos de Graduação, Mestrado e Doutorado em Direito da Universidade Regional do Noroeste do Estado do Rio Grande do Sul - UNIJUÍ e do Curso de Graduação em Direito da Faculdade CNEC Santo Ângelo. Professor Colaborador dos Cursos de Mestrado e Doutorado em Direito da URI, Santo Ângelo. Editor-chefe da Revista Direitos Humanos e Democracia (B1). Avaliador Inep/Mec.

Endereço profissional: DCJS - UNIJUI, Rua do comércio, 3000, bairro universitário. Ijuí, RS. Cep: 98700-000, Brasil.

ORCID ID: https://orcid.org/0000-0003-3703-3052.

E-MAIL:doglasl@unijui.edu.br

Recebido: $22 / 04 / 2020$

Aceito: 05/08/2020

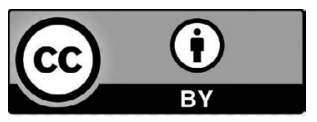

Este trabalho está licenciado sob uma licença Creative Commons Attribution 4.0 International License.

Autores e autoras cedem à Revista Sequência direitos exclusivos de primeira publicação, ficando o trabalho licenciado sob a Creative Commons Attribution 4.0 International License. A licença autoriza que terceiros remixem, adaptem e ou criem a partir do trabalho publicado, indicando o crédito ao trabalho original e sua publicação inicial. Os autores têm permissão para assumir contratos adicionais em separado, com distribuição não exclusiva da versão publicada na Revista Sequência, indicando, de todo modo, a autoria e publicação inicial neste periódico. 